\title{
COMPORTAMENTO DE ESPÉCIES DE EUCALIPTOS PARA REFLORESTAMENTO NA REGIÃO DA ALTA PAULISTA
}

\author{
Fernando Takayuki Nakayama ${ }^{1}$
}

\section{Denilson Burkert ${ }^{2}$}

\section{Danilo Marcelo Aires dos Santos ${ }^{3}$}

\begin{abstract}
Resumo: A eucaliptocultura é uma atividade de destaque em termos nacionais, gerando divisas significativas. Apesar do gênero Eucalyptus possuir centenas de espécies na sua região de origem, menos de dez são usualmente plantadas no Brasil e devido à diversidade de climas e solos, é fundamental o amplo teste destas espécies para avaliar sua adaptabilidade, crescimento e potencial de uso pelos produtores rurais. Desse modo, A inserção de novos materiais na região Nova Alta Paulista tem como objetivo aumentar o leque de opções para produtores da região, demonstrando finalidades e recomendações das mais diversas densidades, finalidades e tipos de madeira, atendendo a demanda sustentável regional de madeira reflorestada. $O$ presente trabalho é conduzido na unidade de pesquisa regional pertencente à APTA PRDTA Alta Paulista, e avalia 18 materiais genéticos entre espécies, clones e híbridos de eucalipto. Foram avaliados altura de plantas, diâmetro de caule, e matéria seca de folhas, caule e raiz. De acordo com os resultados obtidos as plantas "estercadas" no plantio têm demonstrado desempenho superior para todas as variáveis avaliadas e As espécies E. urophylla I e II, E. camaldulensis, híbridos E. urograndis E. urophylla $x$ E. grandis e o clone Piracicaba III têm de maneira geral se destacado à campo.
\end{abstract}

Palavras-chave: Eucalipto. Reflorestamento. Alta Paulista.

\footnotetext{
${ }_{1}^{1}$ Doutor, APTA PRDTA Alta Paulista, pesquisador científico. E-mail.fnakayama@apta.sp.gov.br

${ }^{2}$ Doutor, APTA PRDTA Alta Paulista, pesquisador científico

${ }^{3}$ Doutor, UNESP Ilha Solteira, pós-doutorando.
} 


\section{INTRODUÇÃO}

A silvicultura é uma atividade de destaque no setor agropecuário, haja visto a demanda de madeira existente para inúmeras finalidades. A região da Alta Paulista apresenta um grande potencial agropecuário, porém em outros tempos não ocorrera um grande incentivo na produção de madeira. Uma das plantas com maior adaptabilidade e grande potencial madeireiro, com um crescente e constante aumento de cultivo é o eucalipto.

Esta planta é oriunda do continente australiano e apresenta mais de 600 espécies, porém menos de 10 são cultivadas no Brasil (Stape, 1991). Devido à diversidade de climas e solos em nosso país, é fundamental o amplo teste destas espécies para avaliar sua adaptabilidade, crescimento e potencial de uso pelos produtores rurais (Ferreira, 1979). Desse modo, A inserção de novos materiais na região Nova Alta Paulista tem como objetivo aumentar o leque de opções para produtores da região, demonstrando finalidades e recomendações das mais diversas densidades, finalidades e tipos de madeira, já que muitas das propriedades rurais da região encontram-se em situação de degradação, depauperamento e áreas ociosas, no qual resultará em uma maior rentabilidade da cultura cultivados nas condições edafoclimáticas representativas da Região da Alta Paulista.

Dentro deste contexto a avaliação regional de materiais genéticos potencialmente produtivos de eucalipto, visando alternativas de fonte de renda para diversas finalidades, proporcionará subsídios para o plantio de espécies melhor adaptadas à condições edafoclimáticas da região. Este fato, aliado às técnicas de manejo, permitirá a exploração de madeira, fazendo com que o produtor regional (na grande maioria, pequenos) possa ter um aumento de lucratividade.

\section{MATERIAL E MÉTODOS}

O presente experimento foi conduzido durante os anos agrícolas de 2006/07, sendo instalado em dezembro de 2006 e avaliado em maio de 2007, em área 
experimental pertencente ao Pólo Regional de Desenvolvimento Tecnológico da Alta Paulista - APTA regional, situada $21^{\circ} 40^{\prime}$ de latitude Sul e $51^{\circ} 08^{\prime}$ a Oeste de Greenwich, com altitude de 415 metros. O solo do local é classificado como argissolo vermelhoamarelo, eutrófico, A moderado, textura arenosa/média e apresentam uma topografia ondulada (EMBRAPA, 1999). O clima da região é do tipo Aw, com estação chuvosa e quente no verão inverno seco, segundo a classificação de Köppen. A precipitação média anual é de $1324 \mathrm{~mm}$ com uma evapotranspiração média de $1176 \mathrm{~mm}$, sendo que na estação chuvosa há excedente de $233 \mathrm{~mm}$ e deficiência de $23 \mathrm{~mm}$ na estação seca, a temperatura média anual é de $22,6{ }^{\circ} \mathrm{C}$ e a umidade relativa do ar entre 70 e $80 \%$ (média anual).

Antes da instalação do experimento foram coletadas amostras de solo da área experimental e realizada a análise química de acordo com metodologia proposta por RAIJ \& QUAGGIO (1983) e posteriormente a área será submetida ao preparo convencional, calagem e adubação fornecida na cova, conforme recomendações de Adubação e Calagem para o Estado de São Paulo (RAIJ et al, 1997). O espaçamento utilizado foi o de 3 metros entre as linhas e 2 metros entre as mudas, o que corresponde a 1.666 mudas por hectare.

A escolha do espaçamento depende, fundamentalmente, do uso final pretendido da madeira (já que implica diretamente em aspectos silviculturais, tecnológicos e econômicos), da disponibilidade hídrica regional, do tipo de material genético adotado e da qualidade operacional silvicultural. Além da adubação de plantio, realizou-se ainda a adubação de cobertura no $3^{\circ}$ mês após o plantio tem por objetivo suplementar o solo com nutrientes indispensáveis à expansão da área foliar e do sistema radicular das plantas, em rápido crescimento, após o período de adaptação das mudas no campo.

O delineamento experimental utilizado foi de blocos ao acaso com 18 tratamentos e três repetições, constituídos pela combinação de 13 espécies, 2 híbridos e 3 clones. As parcelas foram constituídas por 4 linhas com 10 plantas cujo espaçamento é 2 metros entre plantas em cada linha e 3 metros de largura entre as linhas (entre linhas), totalizando 40 plantas por parcela com total de 240 metros quadrados por parcela. Serão avaliadas 20 plantas dentro da parcela ao acaso. Os materiais genéticos avaliados foram E. brassiana, E. camaldulensis, E. citriodora, E. ecxerta, E. tereticornis, E. propinqua, 
Clone Piracicaba I, Clone Piracicaba II, Clone Piracicaba III, E. botryoides, E. dunnii, E. grandis, E. grandis x urophylla, E. robusta, E. saligna, E. urophylla I, E. urophylla II e E. urograndis.

As operações realizadas durante o plantio constaram de subsolagem realizada por subsoladores realizando o suco apenas na linha do plantio, a uma profundidade de 40 a $60 \mathrm{~cm}$, adubação seguindo recomendações do Boletim técnico 100 para atender a demanda nutricional do eucalipto e aplicação de $1 \mathrm{~kg}$ de esteco de galinha por metro de sulco para os tratamentos estercados.

Após a aplicação e incorporação dos fetilizantes foi realizado fechamento dos sulcos de plantio e posteriormente o plantio das mudas. Realizou-se ainda o controle de plantas daninhas com a aplicação de herbicidas recomendados, capina manual e coroamento quando necessários. Realizou-se ainda o controle de formigas cortadeiras representadas principalmente pelos gêneros Atta (Saúva) e Acromyrmex (Quenquém), com a aplicação de iscas seguindo recomendações do fabricante.

As avaliações realizadas objetivaram identificar o desenvolvimento vegetativo inicial e visualizar diferenças dentre os materiais avaliados. Avaliou-se altura de plantas, diâmetro de caule, massa de matéria seca de folhas, caule e sistema radicular. Para altura, utilizou-se trena fixa verificando os valores entre o nível da superfície do solo até o ponto mais alto da planta; Para diâmetro de caule, utilizou-se um paquímetro digital, mensurando a $30 \mathrm{~cm}$ do solo; Para massa de matéria seca de folhas, caule e raiz, utilizou-se facão, cortando 10 plantas por repetição, no qual foram separadas folhas, caule e raiz, picados, secos em estufa de circulação forçada por 72 horas a $65^{\circ} \mathrm{C}$, e pesadas em balança de precisão. Os valores médios encontrados estão apresentados nas tabelas abaixo.

\section{RESULTADOS E DISCUSSÃO}


Tabela 01. Valores de médias para altura de plantas $(\mathrm{m})$ e diâmetro de caule $(\mathrm{cm})$ de 18 materias genéticos de eucalipto em função da aplicação ou não de esterco de galinha. Adamantina-SP, Maio de 2007.

\begin{tabular}{ccccc}
\hline Variáveis & \multicolumn{2}{c}{ Altura $(\mathbf{m})$} & \multicolumn{2}{c}{ Diâmetro $(\mathbf{m m})$} \\
\hline Espécies & C/ esterco & S/ esterco & C/ esterco & S/ esterco \\
\hline E. brassiana & 1,50 & 1,43 & 1,37 & 1,30 \\
E. camaldulensis & 1,90 & 1,55 & 2,56 & 1,78 \\
E. citriodora & 1,42 & 1,32 & 1,66 & 1,46 \\
E. ecxerta & 1,39 & 1,37 & 1,27 & 1,14 \\
E. tereticornis & 1,67 & 1,31 & 2,36 & 1,91 \\
E. propinqua & 1,37 & 1,39 & 2,35 & 2,35 \\
Clone Piracicaba I & 1,01 & 1,31 & 1,86 & 2,13 \\
Clone Piracicaba II & 1,40 & 1,04 & 1,91 & 1,43 \\
Clone Piracicaba III & 1,56 & 1,52 & 2,71 & 2,20 \\
E. botryoides & 1,41 & 1,15 & 2,36 & 1,61 \\
E. dunnii & 1,62 & 1,42 & 2,39 & 2,07 \\
E. grandis & 1,40 & 1,31 & 2,08 & 1,89 \\
E. grandis x urophyIlla & 1,79 & 1,57 & 2,97 & 2,19 \\
E. robusta & 1,16 & 1,18 & 2,01 & 1,82 \\
E. saligna & 1,58 & 1,13 & 2,33 & 1,76 \\
E. urophylla I & 1,66 & 1,53 & 2,32 & 2,25 \\
E. urophylla II & 1,57 & 1,70 & 2,96 & 3,11 \\
E. Urograndis & 1,62 & 1,50 & 2,53 & 2,27 \\
Valores médios & 1,50 & 1,37 & 2,23 & 1,54 \\
\hline
\end{tabular}

Para altura de plantas, observa-se um desenvolvimento inicial superior para os tratamentos estercados de maneira geral, superando em 9,5\% para altura de plantas os tratamentos não estercados. Dentre as espécies o E. camaldulensis superou os demais matérias genéticos obtendo os maiores valores médios para altura de plantas. Observa-se que as matérias provindos do E. urophylla e cruzamentos deste apresentaram valores de 
altura de plantas que superaram as demais espécies. Estes resultados demonstra que estes híbridos como o E. urograndis e E. grandis $x$ urophylla são interessantes do ponto de vista regional, já que possuem densidade de madeira superior ao $E$. camaldulensis e ótima qualidade de madeira, possuindo ampla aptidão de uso.

Para diâmetro de caule, os tratamentos estercados apresentaram valores médios $15 \%$ superior aos tratamentos não estercados. Dentre os materiais genéticos, $O E$. urophylla II apresentou os maiores valores para diâmetro, seguido por $E$. grandis $x E$ urophylla e clone Piracicaba III. Este clone se torna interessante regionalmente pois além de produzir madeira no geral ainda apresenta uma excelente opção para apicultores, já que produz um ótimo e duradouro florescimento, matéria prima para a produção de mel.

Tabela 02. Valores de médias para massa de matéria seca de folhas (g), sistema radicular (g) e parte aérea menos folhas $(\mathrm{g})$ de 18 materias genéticos de eucalipto em função da aplicação ou não de esterco de galinha. Adamantina-SP, Maio de 2007.

\begin{tabular}{ccccccc}
\hline & \multicolumn{2}{c}{ folhas (g) } & \multicolumn{2}{c}{ Sistema radicular (g) } & \multicolumn{2}{c}{ Parte aérea s/ folha (g) } \\
\hline & C/ esterco & S/ esterco & C/ esterco & S/ esterco & C/ esterco & S/ esterco \\
\hline E. brassiana & 47,0 & 59,4 & 38,9 & 38,2 & 53,5 & 60,0 \\
E. camaldulensis & 155,5 & 114,6 & 165,6 & 85,4 & 179,2 & 124,0 \\
E. citriodora & 70,1 & 46,5 & 44,0 & 23,3 & 82,1 & 53,1 \\
E. ecxerta & 30,0 & 22,6 & 16,4 & 13,4 & 31,5 & 28,2 \\
E. tereticornis & 101,2 & 63,6 & 79,1 & 56,8 & 141,4 & $\mathbf{7 3 , 8}$ \\
E. propinqua & 55,3 & 105,1 & 37,3 & 47,8 & 80,9 & 137,6 \\
Clone Piracicaba I & 92,5 & 72,4 & 51,2 & 42,3 & 108,0 & 115,2 \\
Clone Piracicaba II & 49,3 & 49,4 & 54,1 & 25,8 & 93,9 & 61,9 \\
Clone Piracicaba III & 80,2 & 65,9 & 63,9 & 49,6 & 157,9 & 117,5 \\
E. botryoides & 59,5 & 40,0 & 48,7 & 22,8 & 114,7 & 66,8 \\
E. dunnii & 83,5 & 69,0 & 67,0 & 44,2 & 150,7 & 96,6 \\
E. grandis & 41,8 & 52,5 & 46,6 & 49,1 & 95,5 & $\mathbf{7 8 , 1}$ \\
E. grandis x urophyIlla & 90,6 & 67,6 & 82,8 & 22,8 & 186,6 & 108,0 \\
E. robusta & 77,6 & 89,5 & 45,0 & 59,8 & 96,6 & $\mathbf{7 8 , 7}$
\end{tabular}




\begin{tabular}{ccccccc} 
E. saligna & $\mathbf{8 2 , 7}$ & 49,3 & 30,2 & 25,4 & 119,3 & 57,3 \\
E. urophylla I & 82,1 & 94,1 & 49,7 & 64,2 & 163,0 & 131,5 \\
E. urophylla II & 62,2 & 188,4 & 102,1 & 60,1 & 140,6 & 205,9 \\
E. Urograndis & 82,4 & 71,3 & 74,6 & 55,2 & 130,4 & 93,7 \\
\hline Valores medios & $\mathbf{7 4 , 6}$ & $\mathbf{7 3 , 4}$ & 61,0 & $\mathbf{4 3 , 7}$ & $\mathbf{1 1 8 , 1}$ & $\mathbf{9 3 , 8}$ \\
\hline
\end{tabular}

Para as avalições de massa de matéria seca de plantas, as médias dos tratamentos estercados apresentaram valores $26 \%$ superiores aos não estercados. A produção superior de massa de matéria seca, indicando maior quantidade de carboidratos fixados e consequentemente uma maior quantidade de $\mathrm{CO}_{2}$ fixado. Torna-se interessante caso o produtor rural regional trabalhe com contratos de comercialização de créditos de carbono. Verificou-se que material genético $E$. urophylla II apresentou as maiores médias de massa de matéria seca da parte aérea, seguido por $E$. camaldulensis e $E$. grandis $x$ urophylla. Para massa do sistema radicular a diferença entre plantas estercadas e não estercadas chegou a 39,5\% sendo o E. camaldulensis seguido de E.urograndis e E. tereticornis as maiores medias de massa de raiz. Resultado este que indica que 0 desenvolvimento vegetativo correlaciona com o desenvolvimento do sistema radicular e que a aplicação do esterco de galinha pode condicionar melhorias do ponto de vista físicos e químicos, proporcionando desta forma um ambiente diferenciado para o desenvolvimento de plantas. Para massa de matéria seca de folhas não foram encontradas diferenças entre plantas estercadas e não estercadas.

\section{CONCLUSÃO}

Todos os materiais genéticos de eucalipto que foram "estercados" no plantio mostrou desempenho superior para: altura de plantas; diâmetro de caule; massa de matéria seca de folhas; massa de matéria seca do sistema radicular; e massa de matéria seca da parte aérea;

As espécies E. urophylla I e II, E. camaldulensis, híbridos E. urograndis, E. urophylla $\times$ E. grandis e o clone Piracicaba III mostraram-se de maneira geral superiores 
aos demais nos primeiros meses de desenvolvimento vegetativo, revelando-se um bom comportamento para a região da Nova Alta Paulista.

\section{REFERÊNCIAS}

EMPRESA BRASILEIRA DE PESQUISA AGROPECUÁRIA (EMBRAPA) Sistema Brasileiro de classificação de Solos. Centro Nacional de Pesquisa de Solos. Rio de Janeiro, 1999, 0412p.

FERREIRA, M. Escolha de espécies de eucalipto. Circular Técnica. IPEF, Piracicaba, v.47, p.1-19, 1979.

KOPPEN, W. 1948. Climatologia: con un estudio de los climas de la tierra. Fondo de Cultura Econômica. México. 479p.

RAIJ, B. Van; QUAGGIO, J.A. Métodos de análise de solo para fins de fertilidade. B. Tec. Instituto Agronômico., 81:1-31, 1983.

RAIJ, B. van; QUAGGIO, J.A.; CANTARELLA, J.; FERREIRA,M.E.; LOPES, A.S.; BATAGLIA, O.A. Análise química do solo para fins de fertilidade. Campinas, Fundação Cargill, 1987, 170p.

STAPE, J.L.; MARTINI, E.L. Desbaste de Eucalyptus: opção de manejo para áreas com limitações ambientais ao corte raso. In: ENCONTRO TÉCNICO FLORESTAL BRACAVE, 5., 1991, Belo Horizonte. Anais. Belo Horizonte: ABRACAVE, 1991. p.30-50. 